Research Article

\title{
Field Tests of Super-Long and Large-Diameter Drilled Shaft Pile Foundations
}

\author{
Peisen Wang, ${ }^{1,2,3}$ Hongyan Ding, ${ }^{1,3}$ Jialin Zhou $\left(\mathbb{D},{ }^{4}\right.$ Wenjun $\mathrm{Hu}^{2}$ Xuechen $\mathrm{Gu}\left(\mathbb{D},{ }^{4}\right.$ \\ and Erwin $\mathrm{Oh}^{4}$ \\ ${ }^{1}$ State Key Laboratory of Hydraulic Engineering Simulation and Safety, Tianjin University, Tianjin, China \\ ${ }^{2}$ School of Civil Engineering, Shandong Jianzhu University, No. 1000 Fengming Road, Jinan 250101, China \\ ${ }^{3}$ School of Civil Engineering, Tianjin University, No. 92 Weijin Road Nankai District, Tianjin 300072, China \\ ${ }^{4}$ School of Engineering and Build Environment, Griffith University, 58 Parklands Dr, Southport, Queensland 4215, Australia
}

Correspondence should be addressed to Jialin Zhou; jialin.zhou@griffith.edu.au

Received 13 March 2020; Accepted 30 April 2020; Published 16 June 2020

Academic Editor: Trung Ngo

Copyright ( $) 2020$ Peisen Wang et al. This is an open access article distributed under the Creative Commons Attribution License, which permits unrestricted use, distribution, and reproduction in any medium, provided the original work is properly cited.

This study investigated the compressive behaviour of super-long pile foundations with large diameters. Three $52 \mathrm{~m}, 73 \mathrm{~m}$, and $83 \mathrm{~m}$ long piles with a diameter of $1500 \mathrm{~mm}, 1500 \mathrm{~mm}$, and $1800 \mathrm{~mm}$ were cast and tested, respectively. Given that large loading was required, an improved compressive static load test was introduced, and the load transfer mechanism, shaft resistance development, and distribution were analysed. This study found that the transferred load decreased along the pile during each applied load, but the gradients were different. For most layers, when increasing the load, the shaft resistance developed in the upper layers first, while the shaft resistance from the lower part did not always fully develop. Moreover, the "mutual compensation" phenomenon was discovered, which was when the shaft softening occurred from one soil layer, the shaft hardening of the other soil would occur simultaneously. Under consideration of the soil layer differences around these piles, it was recommended that shaft and base grouting should be applied on $52 \mathrm{~m}$ and $73 \mathrm{~m}$ piles, while only shaft grouting should be applied on the $83 \mathrm{~m}$ pile. For this longest pile design, whose toe resistance was discovered to be very small, increasing the pile length was not appropriate; thus, it was preferable to increase the pile diameter to increase the ultimate bearing capacity.

\section{Introduction}

A compressive loaded pile is a slender element that transfers the loading from the upper structure to the soil layers. Nowadays, because pile foundations with large capacities are required, increasing the numbers of super-long and large-diameter piles is being considered for high-rise buildings and bridge projects. Usually, in China, a pile longer than 50 metres with a diameter greater than 0.8 metres is recognised as a super-long and large-diameter pile foundation [1]. Lin, Xiong, and Wang [2] pointed out that the pile with a length-to-diameter ratio of 100 or more, though the length may be less than 50 metres, can also be deemed as a super-long pile in practice.

Numerous studies have been conducted to examine the compressive loaded piles including encompassing $\mathrm{H}$-steel piles, pretensioned spun high-strength concrete $(\mathrm{PHC})$ piles, and cast in situ piles with postgrouting [3-7]. Most of the research has focused on the behaviour of these piles with respect to different geotechnical conditions, driving process, analytical method, theoretical load transfer method, and finite element method [8-13]. Previous investigations also include the selfbalanced testing method, determination of the effective length, effect of soil stiffness and negative skin friction of the large diameter, and supper-long pile foundation $[9,14-16]$.

Field tests are the most accurate methods to provide valuable information, such as pile capacity and the load transfer mechanism. However, it is preferable to perform these tests on piles less than 40 metres in length. For a superlong pile, the capacity always achieves up to $10,000 \mathrm{kN}$, which means that more than 1,000 tons of reaction systems are required. Thus, when using a weighted platform, the platform is unsafe and prone to collapse. Moreover, when 
using reaction beams, the beams are prone to fail because the bending movement is too great. Under such conditions, other test methods are preferred, such as dynamic load tests and $\mathrm{O}$-cell tests. However, these tests have some limitations. Some types of pipe piles or $\mathrm{H}$-steel piles, which do not contact the rock, may behave different under dynamic and static loading conditions [17]. For O-cell testing, many engineers believe that the method is too costly because the $\mathrm{O}$-cell is cast inside the pile (and is not recyclable) and the pile will be damaged after the load is applied.

This paper presents a case study referring to super-long and large-diameter piles and introduces an improved static load test (SLT) method. In this research, three drilled shaft pile foundations with various lengths and diameters were tested in a construction project. Their behaviour relating to the load transfer mechanism and shaft resistant development and distribution was analysed. It is expected that the results of this paper will provide practical information for geotechnical engineers.

\section{Compressive Static Load Tests}

Three drilled shaft concrete piles with the labels P12, P66, and P105 were tested in this project. The soil layers were determined through borehole logs near the tested piles. Based on the elevation of each layer, strain gauges (rebar) were installed in each layer to determine the shaft resistance. In contrast to the traditional reaction anchoring system, the test beams (as illustrated in [18]) or reaction beams (as illustrated in [19]) were replaced with a new reaction device developed by Henan Jiaoyuan Engineering Testing Technology Co. Ltd (Patent: ZL 201720239128.2). After construction of the anchoring piles and setting up the test equipment, the maintained compressive SLTs were performed.

2.1. Geotechnical Condition. The bridge project was constructed in Henan Province, China. The subsurface exploration was conducted based on the Specifications for Highway Engineering Geological Remote Sensing (JTG/T C21-01-2005, 2005) and the Standard for Soil Test Method (GB/T50123-1999, 1999). Based on the interpretation of borehole logs, the soil layers near these three tested piles were determined as illustrated in Figure 1. It was found that the main layers were dense to very dense sand and silty sand. Further, it was found that the thickness of the soil layers varied, and the soil layers were loose in the very upper region and dense to very dense in the rest of the region. As shown in Figure 1, all three piles were embedded in the bearing stratum with a depth of 1 meter. The bearing stratum is dense sand, very dense grit, and dense grit for P12, P66, and P105, respectively. Further, in order to determine the shaft resistance, four strain gauges were symmetrically installed in each soil layer.

2.2. Description of Tested Drilled Shaft Pile. Figure 1 presents information of the tested piles. As shown in the figure, the diameter of P12 and P66 is the same which is $1500 \mathrm{~mm}$ and the diameter of P105 is $1800 \mathrm{~mm}$. The pile lengths varied, the shortest pile is $52 \mathrm{~m}$, the medium length pile is $73 \mathrm{~m}$, and the longest pile is $83 \mathrm{~m}$. All pile foundations were made of concrete with the same concrete strength of $30 \mathrm{MPa}$. The designed capacity for P12, P66, and P105 is $28,000 \mathrm{kN}$, $40,000 \mathrm{kN}$, and $64,000 \mathrm{kN}$, respectively, and the reaction frame capacity is designed to be 1.2 times the designed capacity which is $33,600 \mathrm{kN}, 48,000 \mathrm{kN}$, and $76,800 \mathrm{kN}$, respectively.

The locations of the strain gauges are also illustrated in Figure 1. Half the amount of strain gauges along the pile shaft is demonstrated in this figure. These locations are selected according to the soil layers' locations. All the strain gauges are installed symmetrically in case failure of data collection. The telltale is also installed in each pile so that the pile end displacement can be determined.

In each pile, the reinforcement ratio from the upper part is twice the lower part. The diameter of the auxiliary steel bar and the main longitudinal steel is $28 \mathrm{~mm}$, and the diameter of the stirrup is $25 \mathrm{~mm}$ (upper part spacing is $100 \mathrm{~mm}$ and the other part is $150 \mathrm{~mm}$ ). Though the total reinforcement ratio of these three tested piles is different, the reinforcement effect is ignored in this research. This is because this paper is researching the capacity under compressive loads, all these applied loads are resisted by concrete material, and the compressive contribution by the steels is very small.

\subsection{Test Setup}

2.3.1. Reaction System. The traditional reaction system (SLT) is mostly used to test piles with a capacity lower than $10,000 \mathrm{kN}$ (or 1,000 tons) to avoid the reaction beams suffering too much bending moment. In this research, the maximum reaction frame capacity required was $76,800 \mathrm{kN}$ (1.2 times the maximum test load); thus, the traditional reaction beam could not be used. Under this condition, a reaction system was designed. As shown in Figure 2, this reaction system contained eight anchoring piles that were connected with the concrete beams and the steel strand. The load on the reaction device (provided by the hydraulic jacks) could be resisted by the steel strand, and the strand force could be resisted by the vertical friction force (by an anchoring pile) and the horizontal force (by a concrete beam). There was a small bending moment acting on the reaction device; hence, the reaction frame capacity was improved. As shown in Figure 3, hydraulic jacks were used to provide loads, and a reaction device was employed. Two reference steel beams were also used, so that dial gauges could be installed.

2.3.2. Experimental Principle. The strain of the rebar can be determined through the ratio between the stress and the modulus of the rebar, as illustrated in equation (1). The stress of the rebar at a time of $i$ can be calculated by using the force values transferred through the rebar over the rebar crosssectional area, as depicted in equation (2). Before the pile foundation is loaded, the initial coefficients $\left(f_{0}\right.$ and $\left.T_{0}\right)$ should be determined. As shown in equation (3), the force 


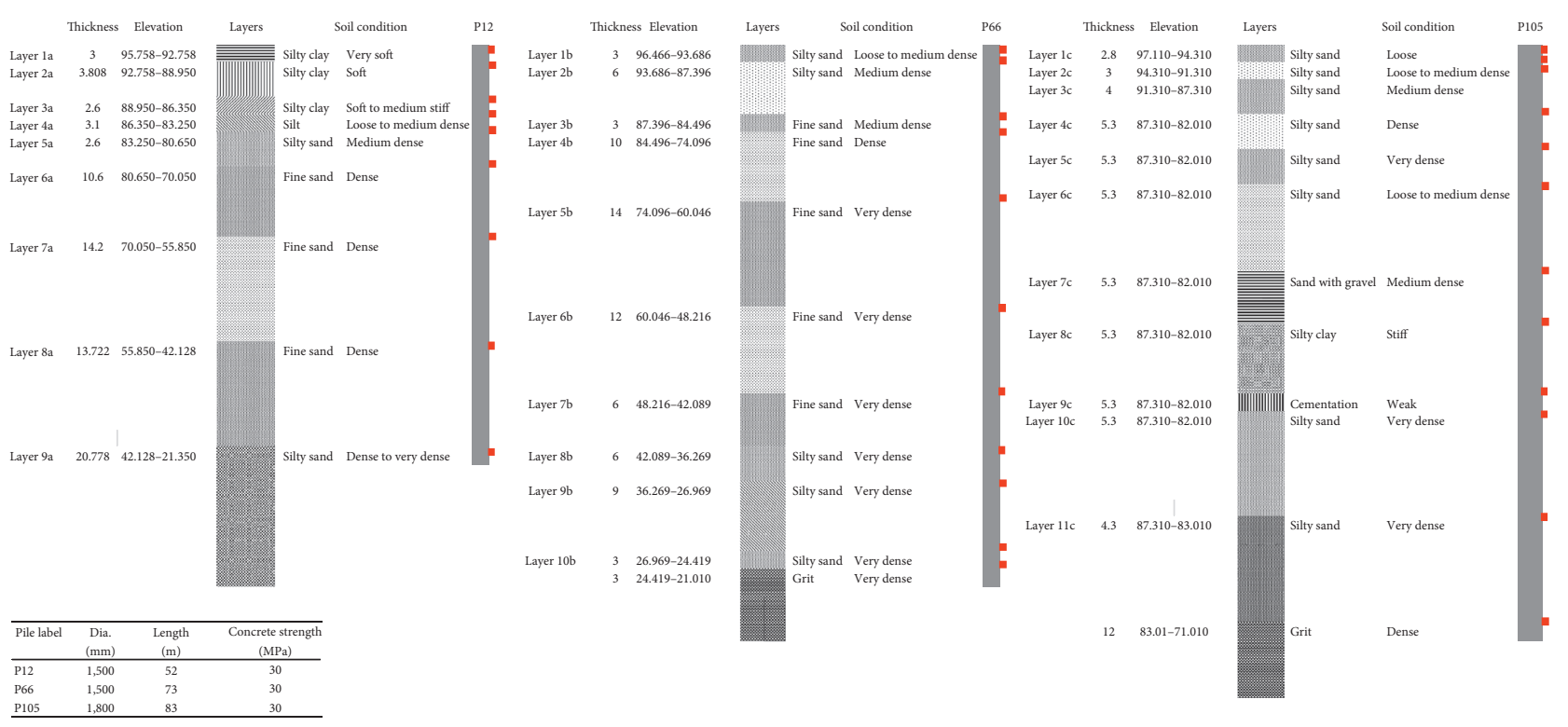

FIgURE 1: Subsurface conditions and tested piles (not to scale).

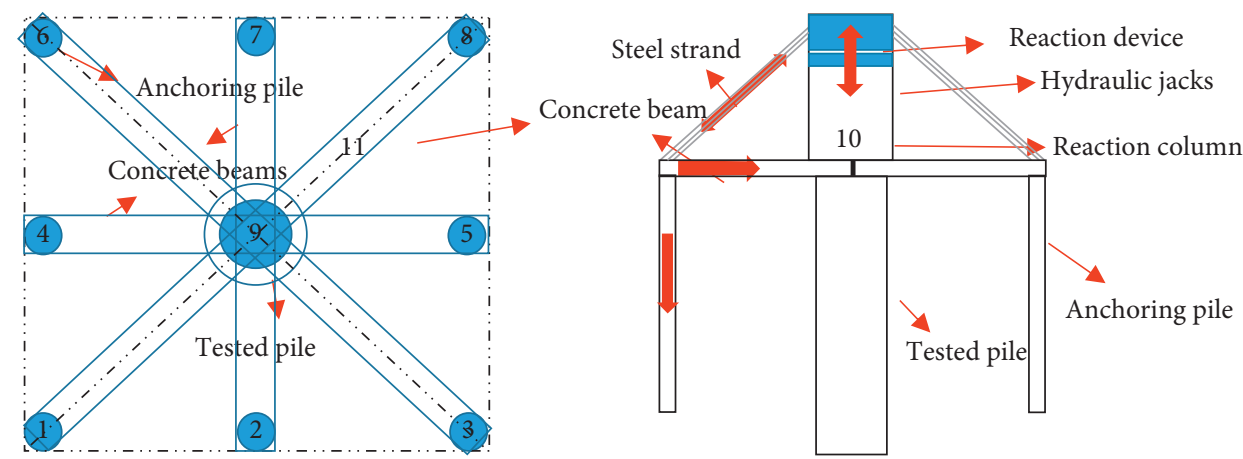

Figure 2: Reaction system design. (a) Plain view of the test setup (not to scale). (b) Mechanical mechanism.

transferred from the pile can be determined after recording the coefficients at a time of $i$. It should be noted that these two initial factors should be recorded after the concrete is cured and the test setup is finished:

$$
\begin{aligned}
\varepsilon_{r i} & =\frac{\sigma_{r i}}{E_{r}}, \\
\sigma_{r i} & =\frac{P_{r i}}{A_{r i}}, \\
P_{r i} & =K\left(f_{i}^{2}-f_{0}^{2}\right)+K_{T}\left(T_{i}-T_{0}\right),
\end{aligned}
$$

where $\varepsilon_{r i}$ is the strain at a time of $i$ developed inside the rebar, $\sigma_{r i}$ is the rebar stress at a time $i$ from the cross area of $A_{r i}\left(\mathrm{kN} / \mathrm{m}^{2}\right), E_{r}$ is the individual rebar modulus provided from the manufacturer $\left(\mathrm{kN} / \mathrm{m}^{2}\right), P_{r i}$ is the vertical force transferred to the rebar $(\mathrm{kN}), A_{r i}$ is the area of the rebar at a time $i\left(\mathrm{~m}^{2}\right), K$ is the calibration coefficient of the rebar $(\mathrm{kN} /$ $\left.\mathrm{Hz}^{2}\right), K_{T}$ is the temperature compensation factor $\left(\mathrm{kN} /{ }^{\circ} \mathrm{C}\right)$, $f_{0}$ is the initial frequency recorded from the rebar $(\mathrm{Hz}), f_{i}$ is the frequency recorded at a time $i(\mathrm{~Hz}), T_{0}$ is the initial temperature $\left({ }^{\circ} \mathrm{C}\right)$, and $T_{i}$ is the temperature at time $i\left({ }^{\circ} \mathrm{C}\right)$.

Theoretically, as shown in equation (4), the strain of the rebar is equal to the strain of the steel reinforcement and the concrete strain after the loading is applied because these three materials act as one element. The concrete crosssectional axial force can be determined from equations (1)-(4), as illustrated in equation (5). The force difference between different concrete cross sections represents the soil friction forces. The friction stress between the concrete pile and soil can be determined as depicted in equation (6):

$$
\varepsilon_{c i}=\varepsilon_{r i}=\varepsilon_{s i},
$$

$$
\begin{aligned}
P_{i} & =A_{c i} E_{c} \varepsilon_{c i}+A_{s i} E_{s} \varepsilon_{s i}=\frac{E_{c} A_{c i}+E_{s} A_{s i}}{E_{s} A_{r i}} P_{r i} \\
& =\frac{E_{c} A_{c i}+E_{s} A_{s i}}{E_{s} A_{r i}}\left[K\left(f_{i}^{2}-f_{0}^{2}\right)+K_{T}\left(T_{i}-T_{0}\right)\right],
\end{aligned}
$$

$$
q_{s}=\frac{\Delta P_{i}}{\Delta A_{s h}}
$$




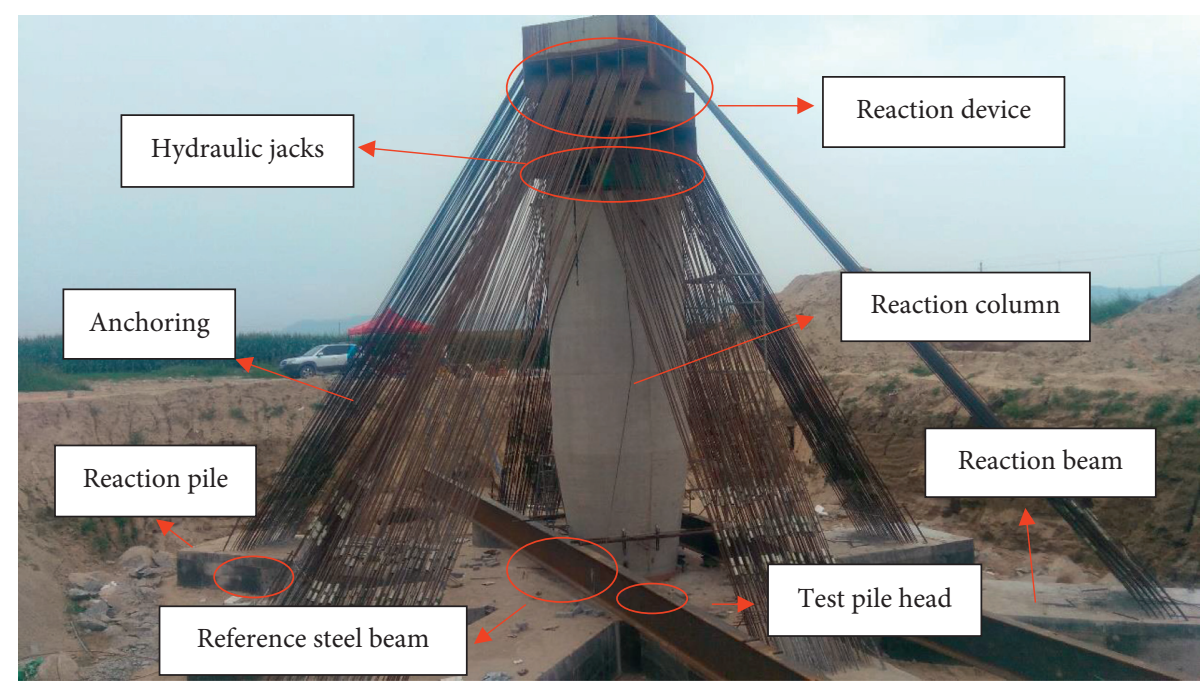

FIGURE 3: Anchoring reaction system.

where $P_{i}$ is the concrete cross-sectional axial force, $A_{c i}, E_{c}$, and $\varepsilon_{c i}$ are the concrete section area, modulus, and strain at a time $i$, respectively, $A_{s i}, E_{s}$, and $\varepsilon_{s i}$ are the steel section area, modulus, and strain at a time $i$, respectively, $q_{s}$ is the friction stress between the concrete pile and soil $(\mathrm{kN} /$ $\left.\mathrm{m}^{2}\right), \Delta P_{i}$ is the force difference between two cross-section axial forces $(\mathrm{kN})$, and $\Delta A_{s h}$ is the column friction area $\left(\mathrm{m}^{2}\right)$.

2.3.3. Construction Process. Figure 4 displays the preparation of the pile test. As depicted in Figure 2(a), eight anchor piles were initially cast and later the test pile was cast. After 28 days of curing, the reaction column was cast. Later, the reaction column, concrete beam, anchoring strand, and test pile were connected, as demonstrated in Figure 2(b). After the installation of hydraulic jacks and dial gauges, the compressive SLT could be performed and finally, the results could be obtained.

2.4. Test Process. The maintained compressive load tests were selected to perform. As shown in Table 1, there were 14, 10 , and 16 loading stages for P12, P66, and P105, with the first loading of $4,000 \mathrm{kN}$, respectively. The number of unloading stages was half the number of the loading stages, and the decrement load was twice the increment load. During each loading stage, the vertical settlement was recorded at time intervals of five minutes, 10 minutes, 15 minutes, 30 minutes, 45 minutes, and one hour. For the unloading stages, the time interval was 30 minutes. Among these recorded values during loading stages, if the difference settlement value was less than $0.1 \mathrm{~mm}$, it could be primarily recognised as a stable condition. If the difference value of $0.1 \mathrm{~mm}$ occurred twice, it could be viewed as stable and the next load could be applied.

\section{Test Results and Discussion}

3.1. Settlement-Lg Time and Load-Settlement Curves. Figures 5-7 display the settlement-lg time of the three tested piles. As indicated in these figures, there were no points that illustrated a dramatic turning trend, and all settlement values during each applied load were close, which demonstrated that these pile foundations were stable during each applied load. As shown in Figure 5, after the maximum loading of $28,000 \mathrm{kN}$ was applied, the maximum vertical pile head settlement of P12 was determined as $87.42 \mathrm{~mm}$. Comparing to P66, as demonstrated in Figure 6, the stable settlement of the P66 was found as $22.92 \mathrm{~mm}$ when loads of $28,000 \mathrm{kN}$ was applied, and the total head settlement was small $(55.49 \mathrm{~mm})$ when maximum loads of $40,000 \mathrm{kN}$ was applied. This represents that the capacity of P66 is greater than P12. Also, this phenomenon illustrated that increasing the pile length, especially when reaching a harder bearing stratum, can effectively increase the ultimate bearing capacity of the single pile. As shown in Figure 7, when a loading of $28,000 \mathrm{kN}$ was applied, the pile head displacement of P105 was determined as $17.10 \mathrm{~mm}$, which was less than P66 (22.92 mm) and P12 $(87.42 \mathrm{~mm})$. Furthermore, when loads of $40,000 \mathrm{kN}$ was applied, the vertical settlement of P105 was determined as $27.33 \mathrm{~mm}$, which was also less than the settlement of P66 $(55.49 \mathrm{~mm})$. This is primarily due to the increment of the pile diameter and the pile length that improves the total capacity of a single pile. In addition, when the pile was loaded $64,000 \mathrm{kN}$, the total settlement of P105 was determined as $45.07 \mathrm{~mm}$ as shown in Figure 7, and this represents that this pile possesses the greatest load capacity. From another point of view, the design of this pile foundation is too conservative ( $45.07 \mathrm{~mm}<0.1 * \mathrm{D}=0.1 * 1800 \mathrm{~mm}=180 \mathrm{~mm})$.

The load-settlement curves of these tested piles in relation to the pile toe are presented in Figures 8-10. As shown in Figure 8, after the maximum loads were applied, the pile toe displacement of P12 was determined as $74.2 \mathrm{~mm}$, which represents that the compression of the concrete is very small. This is because the bearing stratum is the silty sand (compressible) as depicted in Figure 1. This also illustrates that the loads have transferred to the pile toe and the transferred loads are resisted by the bearing stratum. As shown in Figure 9, the pile toe movement of P66 was determined as $21.73 \mathrm{~mm}$ (ratio between toe and head 


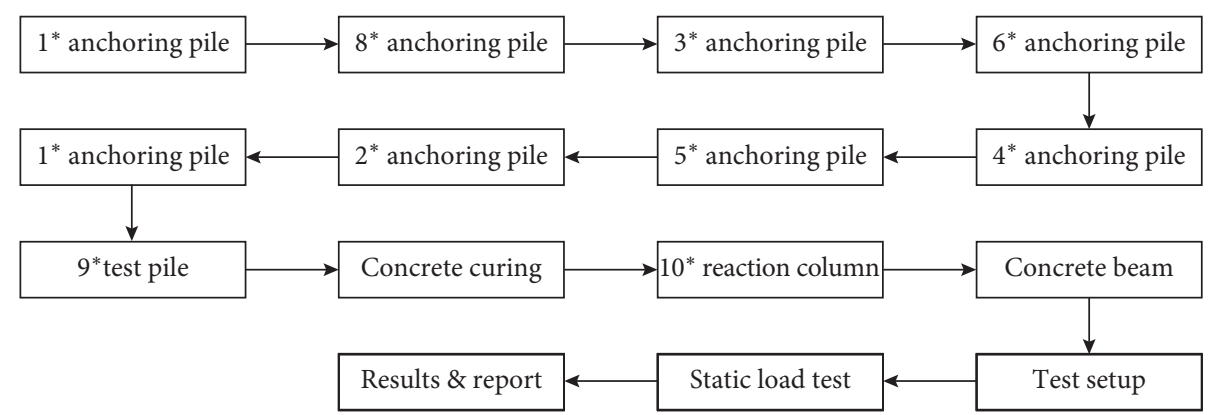

FIGURE 4: Construction process.

TABLE 1: Information of the test process.

\begin{tabular}{lccccc}
\hline Pile label & Loading stage & Unloading stage & First load $(\mathrm{kN})$ & Increment $(\mathrm{kN})$ & Decrement $(\mathrm{kN})$ \\
\hline P12 & 14 & 7 & 4,000 & 2,000 & 4,000 \\
P66 & 10 & 5 & 4,000 & 4,000 & 8,000 \\
P105 & 16 & 8 & 4,000 & 4,000 & 8,000 \\
\hline
\end{tabular}

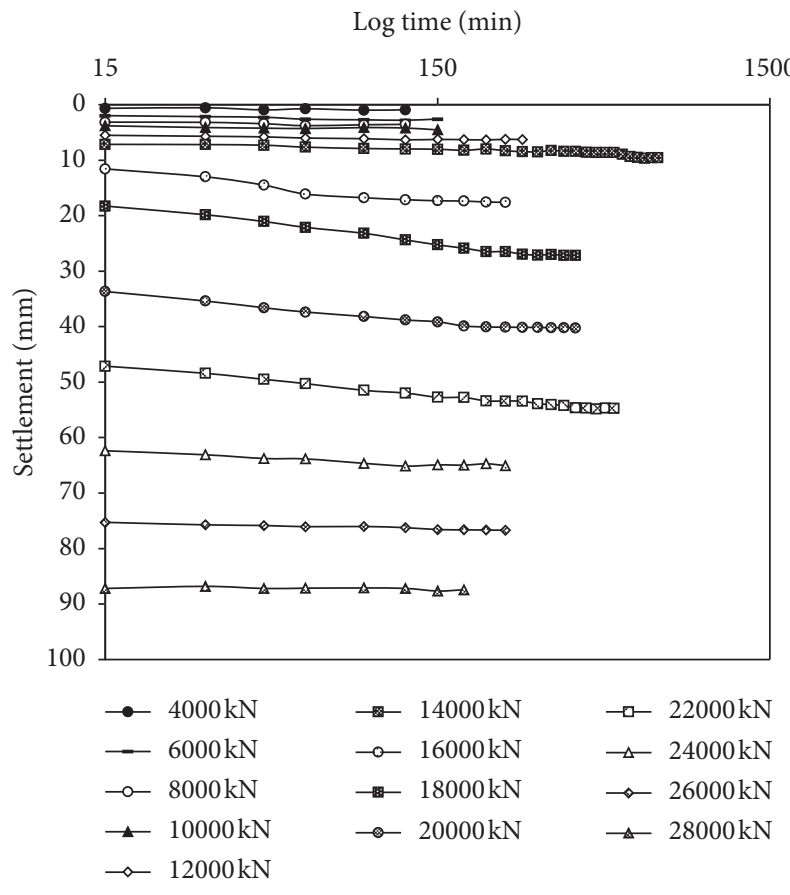

Figure 5: S-lgt results of P12.

settlement: $21.73 / 55.49=39 \%$ ). Two reasons may have led to this phenomenon, the first one is that the bearing stratum is very dense grit; the second reason is that the shaft friction decreases the transferred load (P66 is longer than P12). As demonstrated in Figure 10, the pile toe displacement of P105 was very small (only $1.59 \mathrm{~mm}$ ). This illustrates that the load did not transfer to the pile toe because this pile is too long; in other words, this pile is designed very conservative.

The load-settlement curves of these tested piles in relation to the pile head are shown in Figure 11. It can be found that, after the maximum loadings of $28,000 \mathrm{kN}, 40,000 \mathrm{kN}$, and $64,000 \mathrm{kN}$ were applied, the maximum settlements of

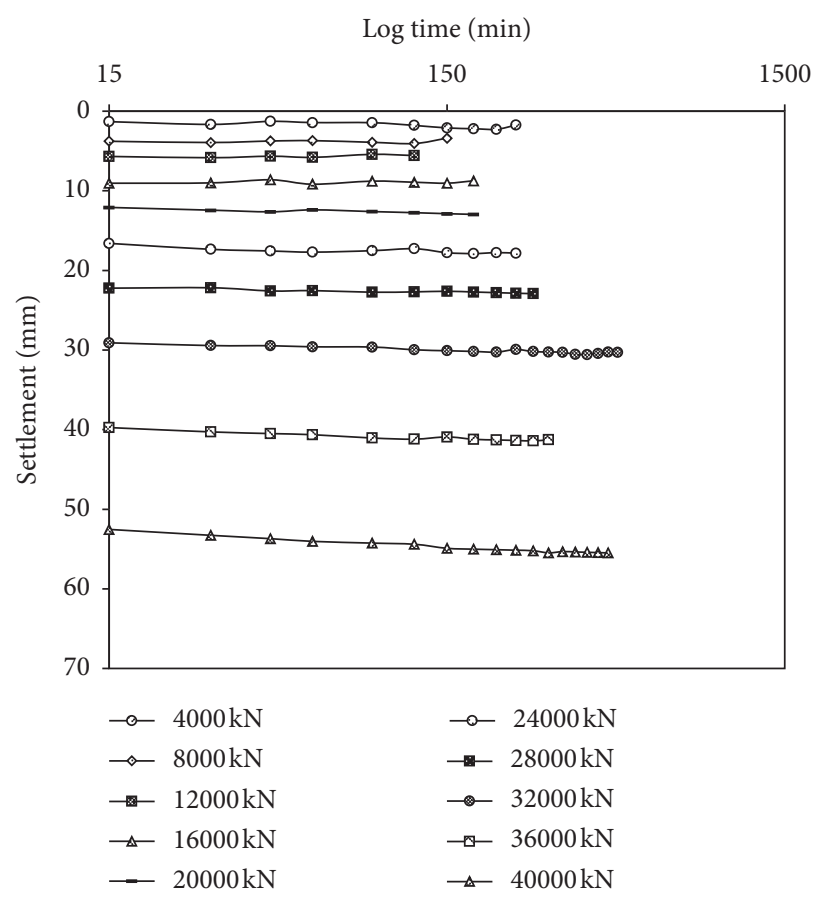

Figure 6: S-lgt results of P66.

P12, P66, and P105 were determined to be $87.42 \mathrm{~mm}$, $55.49 \mathrm{~mm}$, and $45.07 \mathrm{~mm}$, respectively. This demonstrates that the pile capacity of P105 is greater than that of the other two piles, and the smallest capacity is for P12. Further, it was found that, for P105, a linear line was observed (close to elastic deformation of PL/EA), which represented that the settlement of P105 was mainly due to compression deformation. Given that the deformation of the concrete element is the main factor indicating the ultimate capacity of a pile (P105), the ultimate bearing capacity would not effectively increase if base grouting technology is applied. 


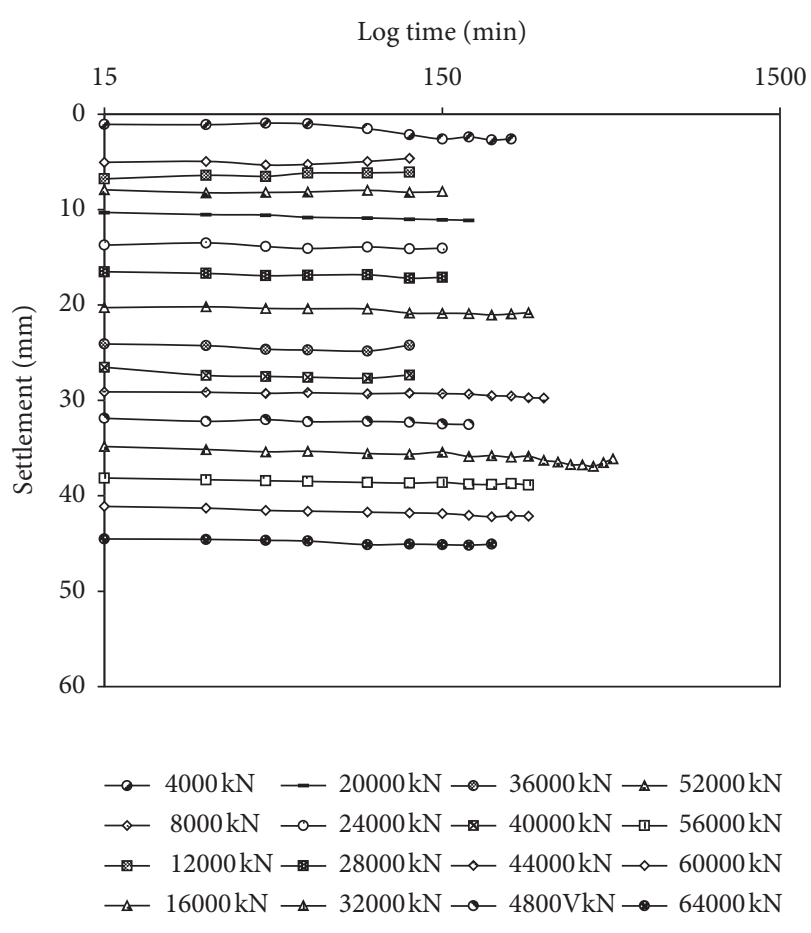

FIGURE 7: S-lgt results of P105.

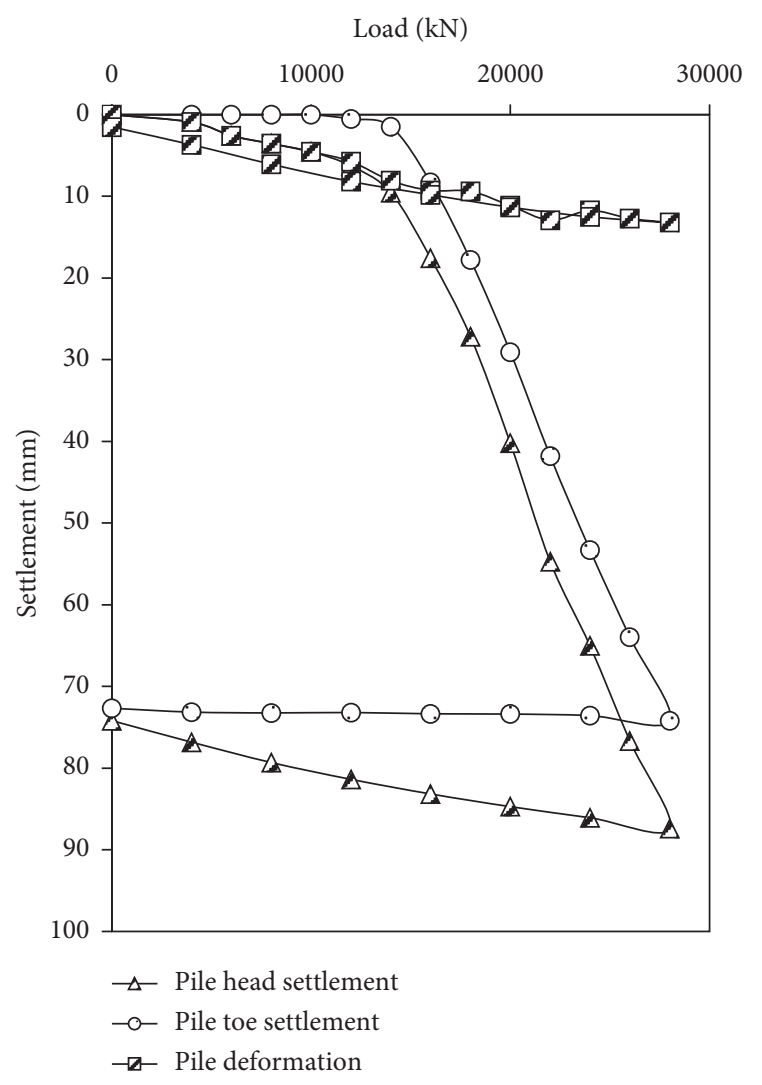

FIGURE 8: Load-settlement curves of P12.

3.2. Load Transfer Mechanism. The load transferred to the pile cross section along the pile length can be determined using equation (5). Figures 12-14 present the load transfer

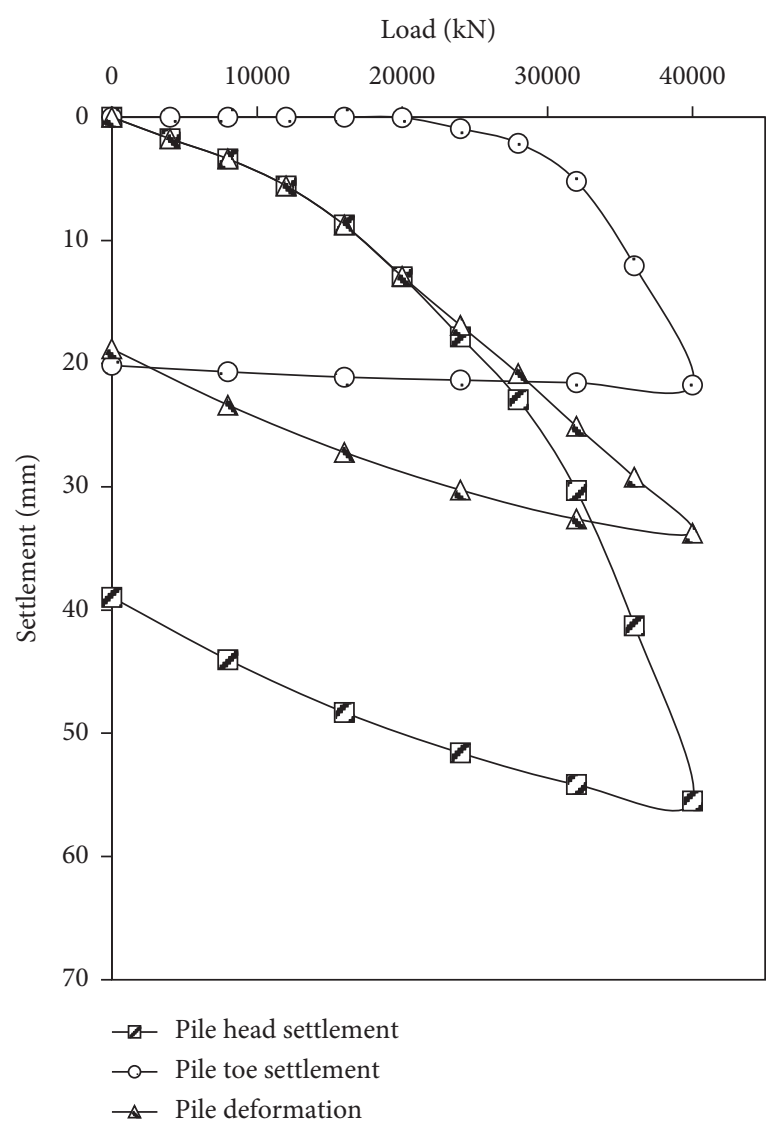

Figure 9: Load-settlement curves of P66.

mechanism of these three tested piles. It can be seen that the transferred load decreased along the pile length during each applied load, but the gradients were different. This was because the pile shaft area and soil layers were different. As shown in Figure 12, the transfer change of the axial force of $\mathrm{P} 12$ from $0 \mathrm{~m}$ to $15 \mathrm{~m}$ was smaller than the rest of the part. This was because the layers from $0 \mathrm{~m}$ to $15 \mathrm{~m}$ were mostly silty clay with soil condition of "very soft and soft." Also, it can be found that below $15 \mathrm{~m}$, the gradients from each layer were similar, and this was due to the existing similar soil layers and conditions (Figure 1, dense fine sand). As shown in Figure 13, the gradients of P66 from $0 \mathrm{~m}$ to $12 \mathrm{~m}$ were greater than the rest of the part, and this was because of the existence of loose sand and soft clay. As shown in Figure 14, the gradient from $0 \mathrm{~m}$ to $10 \mathrm{~m}$ was large, which illustrates a small change of axial force. This was because the loose to medium dense sand existed in this range. Also, the smallest gradient was found from $30 \mathrm{~m}$ to $38 \mathrm{~m}$, and this was due to the stiff soil layer existing in this range and more shaft resistance was provided by this layer.

For P12 and P66, the bearing capacity included the end bearing as demonstrated in Figures 12 and 13, respectively. Further, it can be found that the end bearing percentage of P12 $(9523 / 28000=34 \%)$ was greater than P66 (8117/ $40000=20.2 \%$ ), which represented that the increase of pile length can contribute to the increase of the shaft resistance and hence reduce the transferred loads to the bearing 


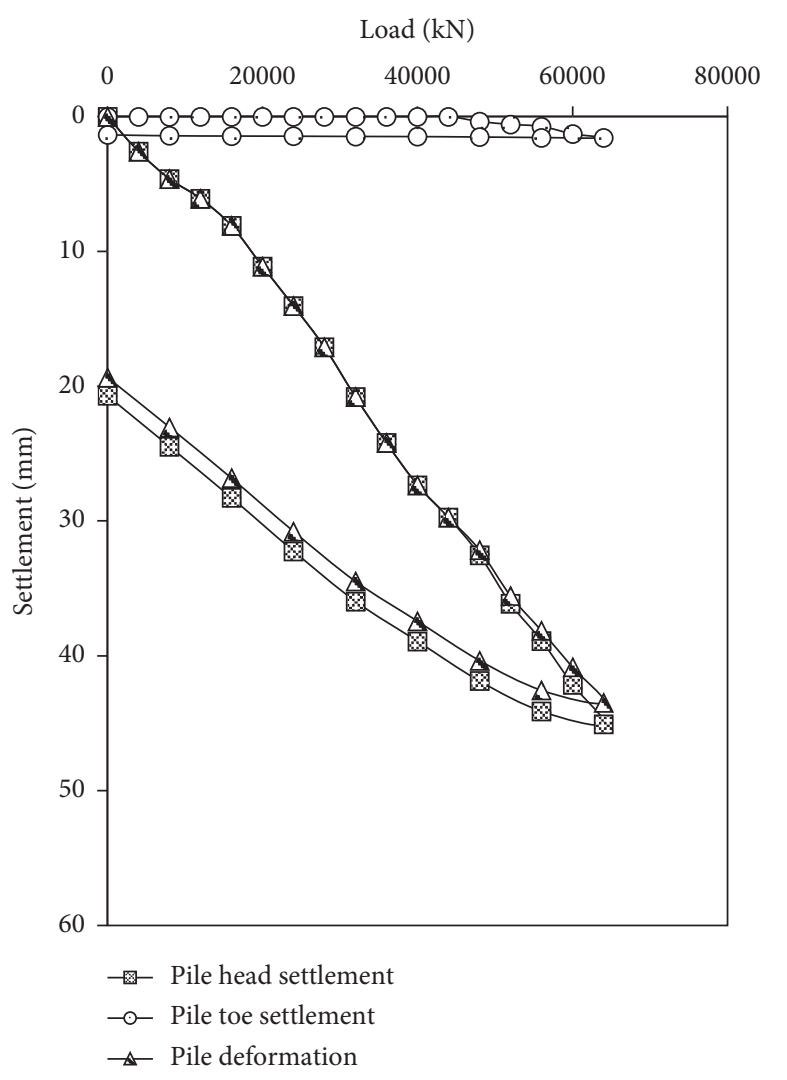

FIGURE 10: Load-settlement curves of P105.

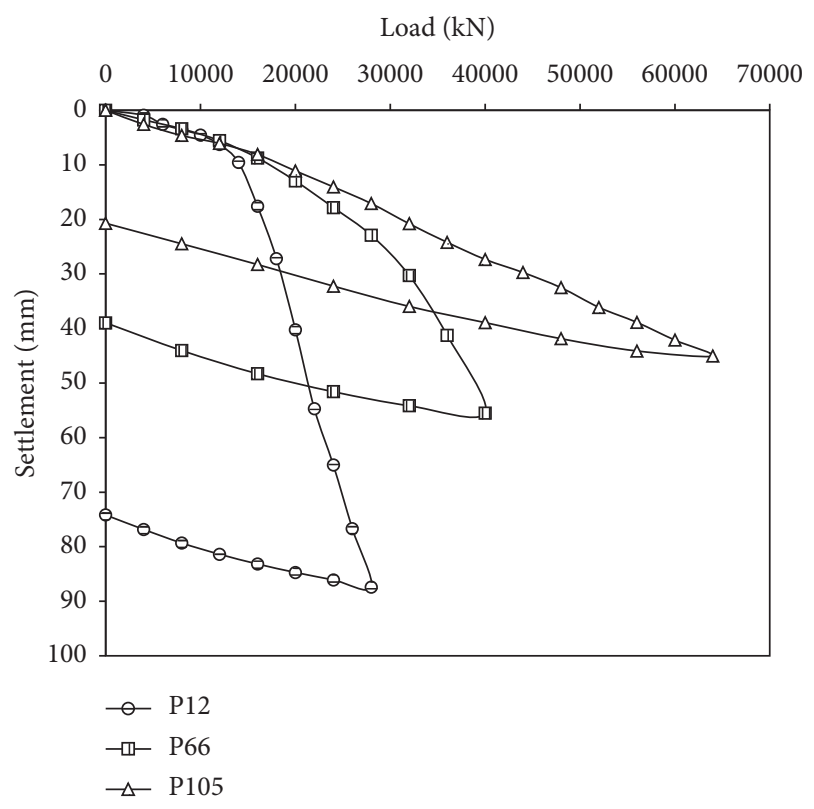

Figure 11: Load-settlement curves of tested piles.

stratum. However, for P105, the end bearing was very small. This indicated that P105 was a shaft resistant pile (Figure 14). Under this condition, seeking to improve the ultimate bearing capacity by base grouting would be pointless for P105. As illustrated in Figure 1, the soil layers around P105

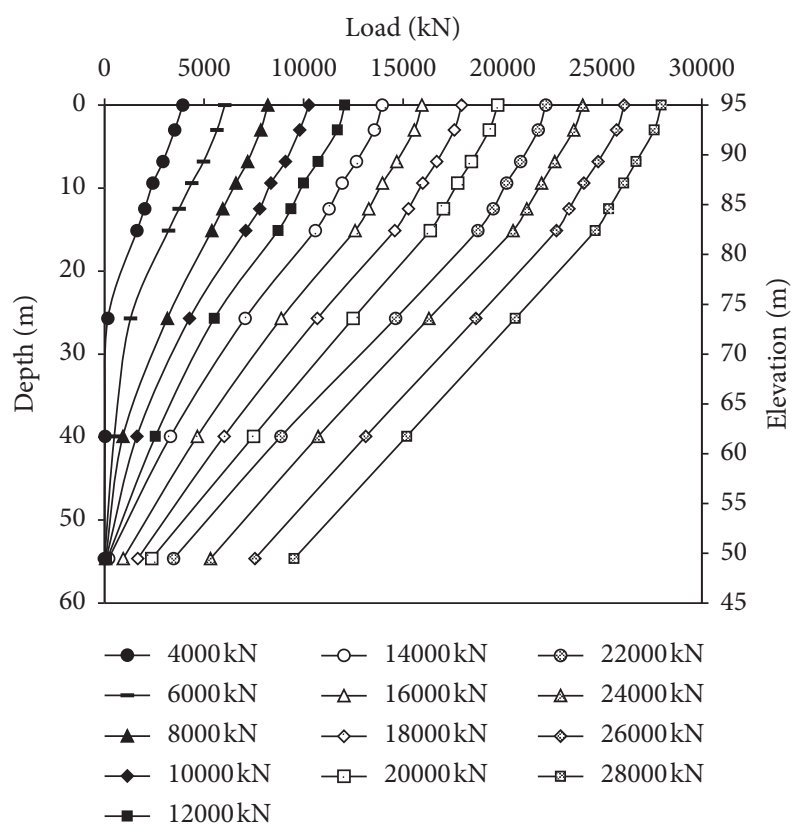

FIGURE 12: Load transfer mechanism of P12.

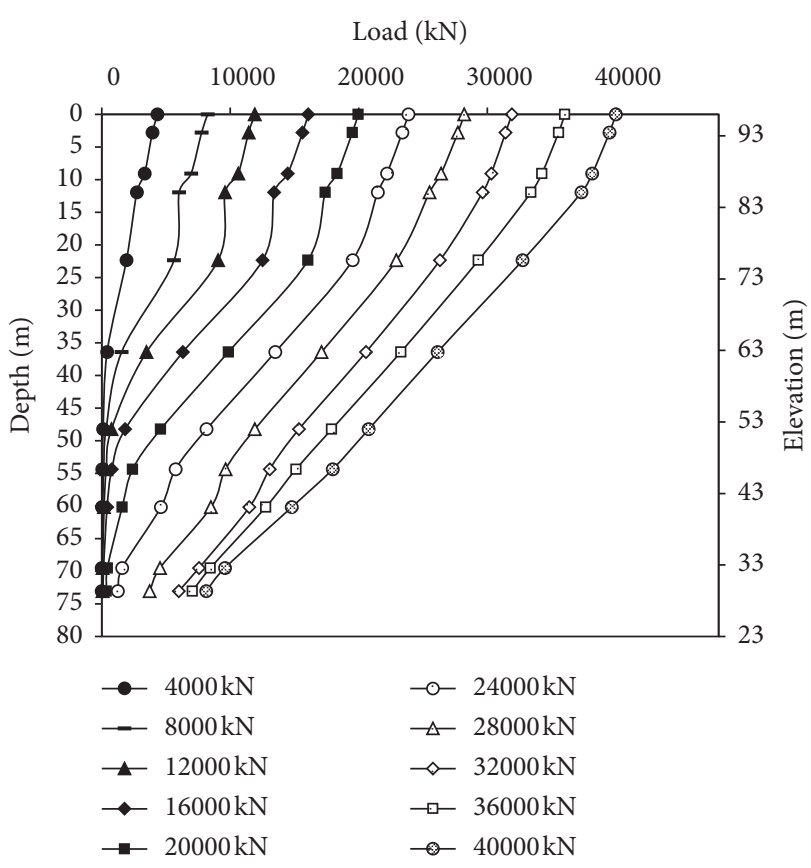

Figure 13: Load transfer mechanism of P66.

were mostly sandy material; thus, shaft grouting technology was preferred to increase the ultimate bearing capacity. In addition, since no loads were transferred to the pile end, increasing the pile length would not increase the pile capacity, and the shaft resistance near the pile toe would not be fully developed.

Table 2 provides the proportion of shaft and toe resistance under each working load. It can be seen that, for P105, a very small end bearing was observed. For P12 and P66, before $R_{\mathrm{W}}$ was less than $80 \%$, the shaft and toe resistance 


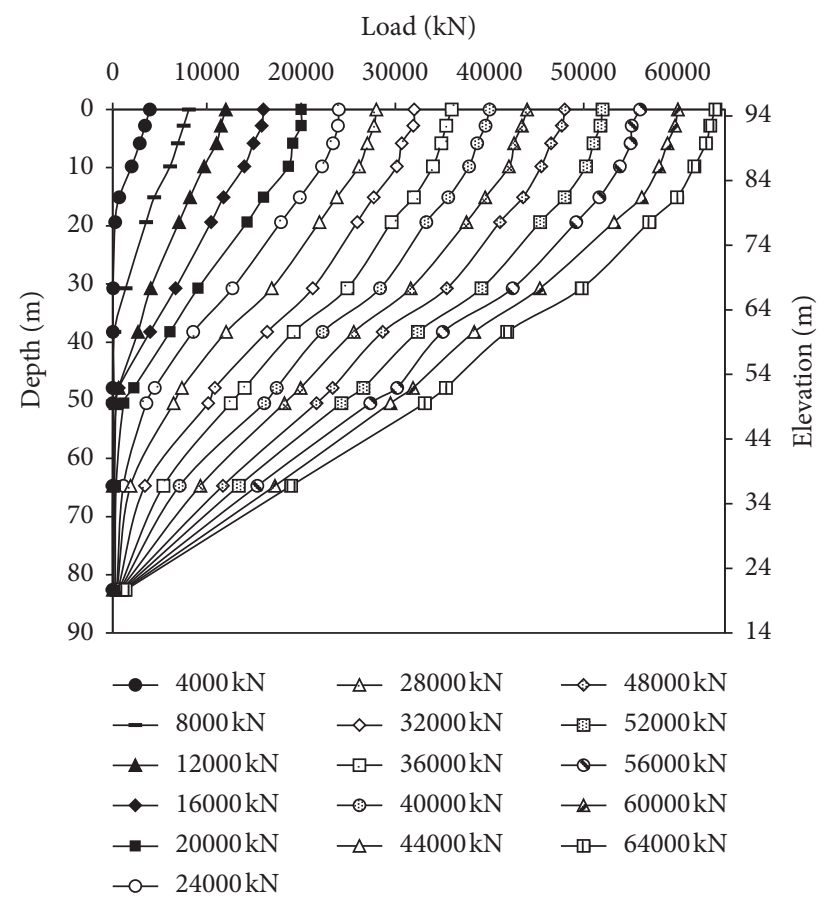

FIGURE 14: Load transfer mechanism of P105.

TABLE 2: Proportion of shaft and toe resistance under working load.

\begin{tabular}{|c|c|c|c|c|c|c|c|c|}
\hline \multicolumn{3}{|c|}{ P105 } & \multicolumn{3}{|c|}{ P66 } & \multicolumn{3}{|c|}{ P12 } \\
\hline$R_{\mathrm{W}(100 \%)}$ & $R_{\mathrm{E}(100 \%)}$ & $R_{\mathrm{S}(100 \%)}$ & $R_{\mathrm{W}(100 \%)}$ & $R_{\mathrm{E}(100 \%)}$ & $R_{\mathrm{S}(100 \%)}$ & $R_{\mathrm{W}(100 \%)}$ & $R_{\mathrm{E}(100 \%)}$ & $R_{\mathrm{S}(100 \%)}$ \\
\hline 6.25 & 0.00 & 100.00 & 10.00 & 0.00 & 100.00 & 14.29 & 0.00 & 100.00 \\
\hline 12.50 & 0.00 & 100.00 & 20.00 & 0.19 & 99.81 & 21.43 & 0.00 & 100.00 \\
\hline 18.75 & 0.00 & 100.00 & 30.00 & 0.39 & 99.61 & 28.57 & 0.63 & 99.38 \\
\hline 25.00 & 0.13 & 99.87 & 40.00 & 0.66 & 99.34 & 35.71 & 0.83 & 99.17 \\
\hline 31.25 & 0.21 & 99.79 & 50.00 & 1.80 & 98.20 & 42.86 & 1.15 & 98.85 \\
\hline 37.50 & 0.27 & 99.73 & 60.00 & 5.18 & 94.83 & 50.00 & 1.46 & 98.54 \\
\hline 43.75 & 0.30 & 99.70 & 70.00 & 13.32 & 86.68 & 57.14 & 5.84 & 94.16 \\
\hline 50.00 & 0.33 & 99.67 & 80.00 & 18.70 & 81.30 & 64.29 & 9.25 & 90.75 \\
\hline 56.25 & 0.53 & 99.47 & 90.00 & 19.56 & 80.44 & 71.43 & 11.84 & 88.17 \\
\hline 62.50 & 0.75 & 99.25 & 100.00 & 20.29 & 79.71 & 78.57 & 15.76 & 84.24 \\
\hline 68.75 & 0.92 & 99.08 & & & & 85.71 & 22.18 & 77.83 \\
\hline 75.00 & 1.02 & 98.98 & & & & 92.86 & 29.07 & 70.93 \\
\hline 81.25 & 1.19 & 98.81 & & & & 100.00 & 34.01 & 65.99 \\
\hline 87.50 & 1.26 & 98.74 & & & & & & \\
\hline 93.75 & 1.47 & 98.53 & & & & & & \\
\hline 100.00 & 1.80 & 98.20 & & & & & & \\
\hline
\end{tabular}

Note. $R_{\mathrm{W}}=$ working load proportion; $R_{\mathrm{E}}=$ end bearing percentage; $R_{\mathrm{S}}=$ shaft resistance percentage.

proportions were similar. Further, when $R_{\mathrm{W}}$ was $100 \%$, the shaft resistance proportion of P12 was less than that of P66, which was mainly because the pile length of P66 was greater than that of P12.

3.3. Shaft Resistance Development and Distribution. Figures 15-17 present the load-shaft resistance curves of the three tested piles in relation to each soil layer. As shown in Figure 15, for P12, it was observed that, for most layers, when increasing the load, the shaft resistance developed from zero to a maximum value and was then maintained.
Moreover, the shaft resistance from the upper layers developed first (the shaft resistance from layer 7 and layer $8 \mathrm{did}$ not well develop before a loading of $8000 \mathrm{kN}$ was applied). Also, it can be found that, after loads of $8000 \mathrm{kN}$ were applied, the shaft resistance from layers 6,7 , and 8 increased dramatically, and the shaft resistance of layers 6 and 7 maintained after loads of $22,000 \mathrm{kN}$ were applied, but the resistance kept increasing for layer 8 , which represented that the total shaft resistances were almost fully developed.

As illustrated in Figure 16, similar to P12, the shaft resistance of P66 from the upper layers developed first. The shaft resistance from layers 1,2, and 3 was fully developed 


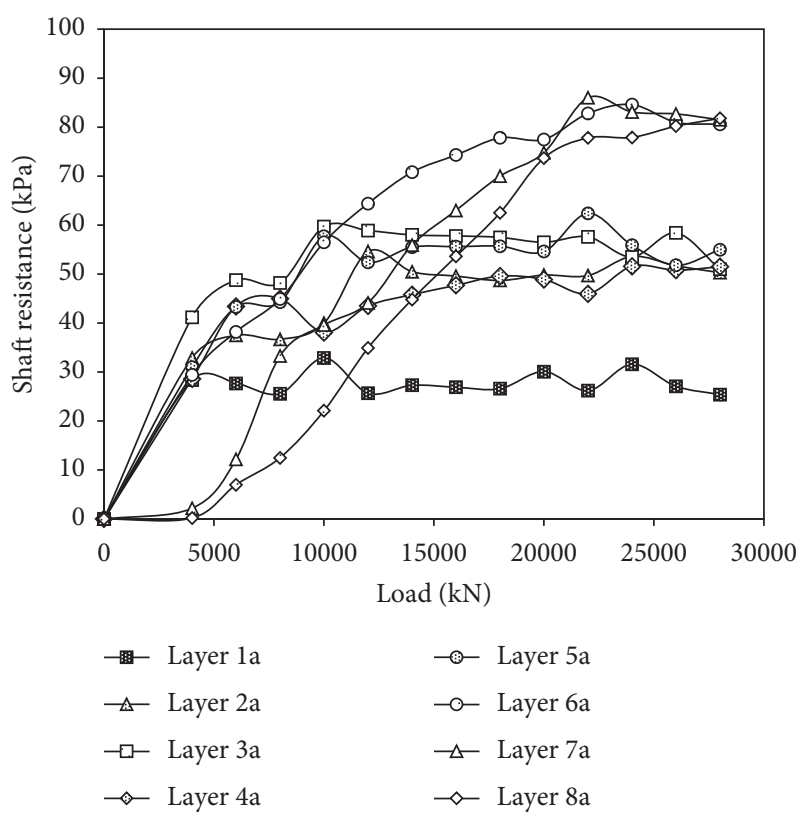

FIgURE 15: Shaft resistance development of P12.

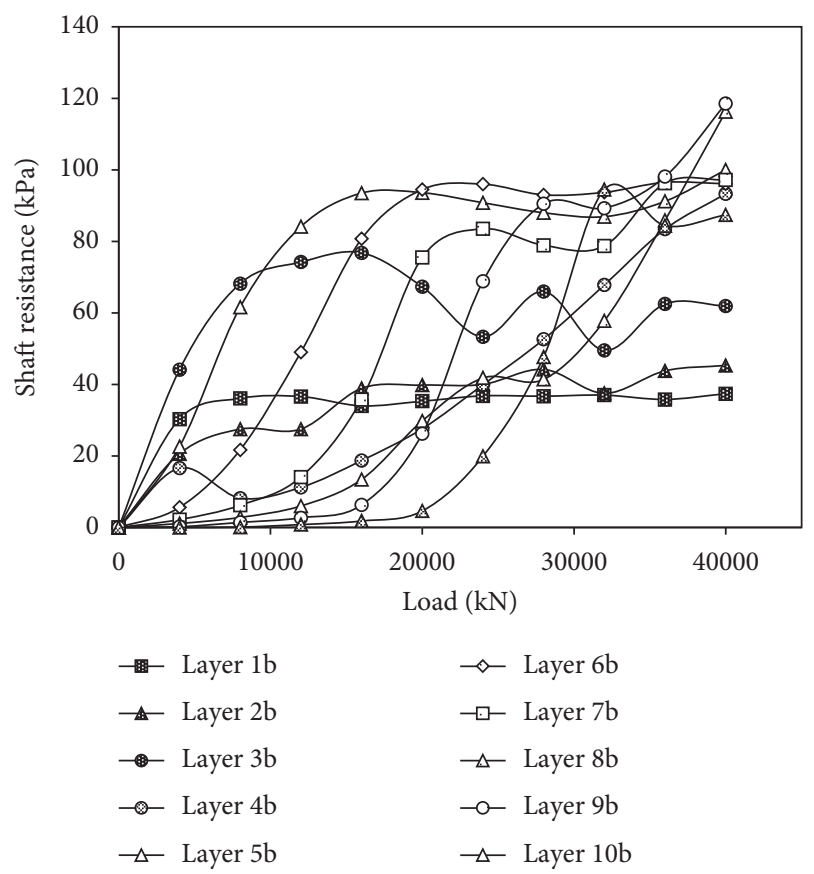

Figure 16: Shaft resistance development of P66.

after $8000 \mathrm{kN}$, and the resistance from layers 8,9 , and 10 started to increase after $16,000 \mathrm{kN}$ was applied. In addition, it was found that some curves fluctuated. As for layer 3, the shaft resisting softening was found when a loading of $16,000 \mathrm{kN}$ was applied, and after $24,000 \mathrm{kN}$, stress hardening occurred. The reason was that the pile was compressed vertically and expanded horizontally when the load was applied, and the sandy soil of layer 3 (medium dense) near the pile rearranged the location. The slippage of the sand particles decreased the development of the shaft resistance,

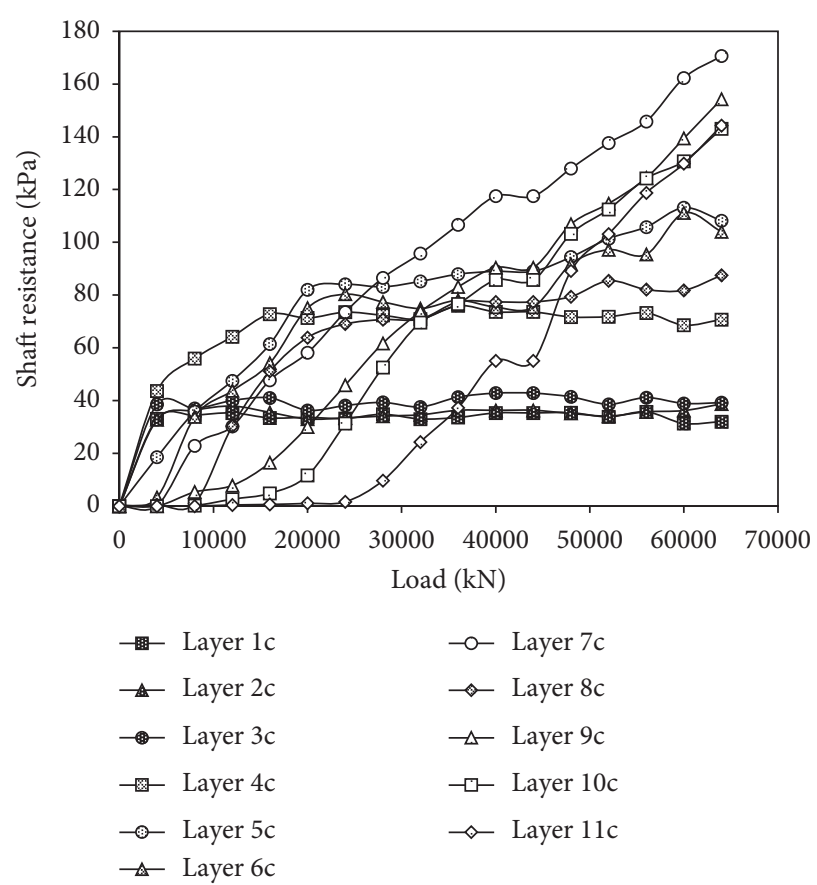

Figure 17: Shaft resistance development of P105.

but later, the soil particles became stable and the shaft resistance developed. Interestingly, the soil softening and soil hardening occurred again as shown in the figure, and the reason may be related to the slurry wall thickness. Unfortunately, those data are limited, and further research referring to the amount of the slurry admixture is required. It is worth to notice that, from the second softening of layer 3 (loading of $32,000 \mathrm{kN}$ ), the shaft resistance of layer 10 increased dramatically, and from the second hardening of layer 3 (loading of $36,000 \mathrm{kN}$ ), the shaft resistance of layer 10 decreased dramatically. This phenomenon can be explained as "mutual compensation".

As demonstrated in Figure 17, it is evident to see that the shaft resistance of layers 1,2 , and 3 was fully developed after $4000 \mathrm{kN}$, and the shaft resistance of layers $4,5,6$, and 8 was fully developed after $20,000 \mathrm{kN}$. Later, with the increasing of pile head loading, the layers $8,9,10$, and 11 played a significant role in resisting the transferred load. Also, it can be seen that the shaft resistance of layer 7 kept increasing (thoughs tress softening occurred which was due to slippage of sand and gravel), and this illustrated that the shaft resistance from the upper layer did not have to be fully developed when the shaft resistance from the lower part started to develop.

Figures 18-20 present the shaft resistance distribution along the pile depth of the tested piles. As shown in Figure 18, before a loading of $10,000 \mathrm{kN}$ was applied, the shaft resistance of P12 was mainly provided by layers 3, 5, and 6 . Moreover, with the loads increasing, the shaft resistance generally developed along the pile length. Similar to the finding obtained from Figure 15, after a loading of 22,000 kN was applied, except for the bottom layer (the shaft resistance have kept increasing), the shaft resistance from the other 


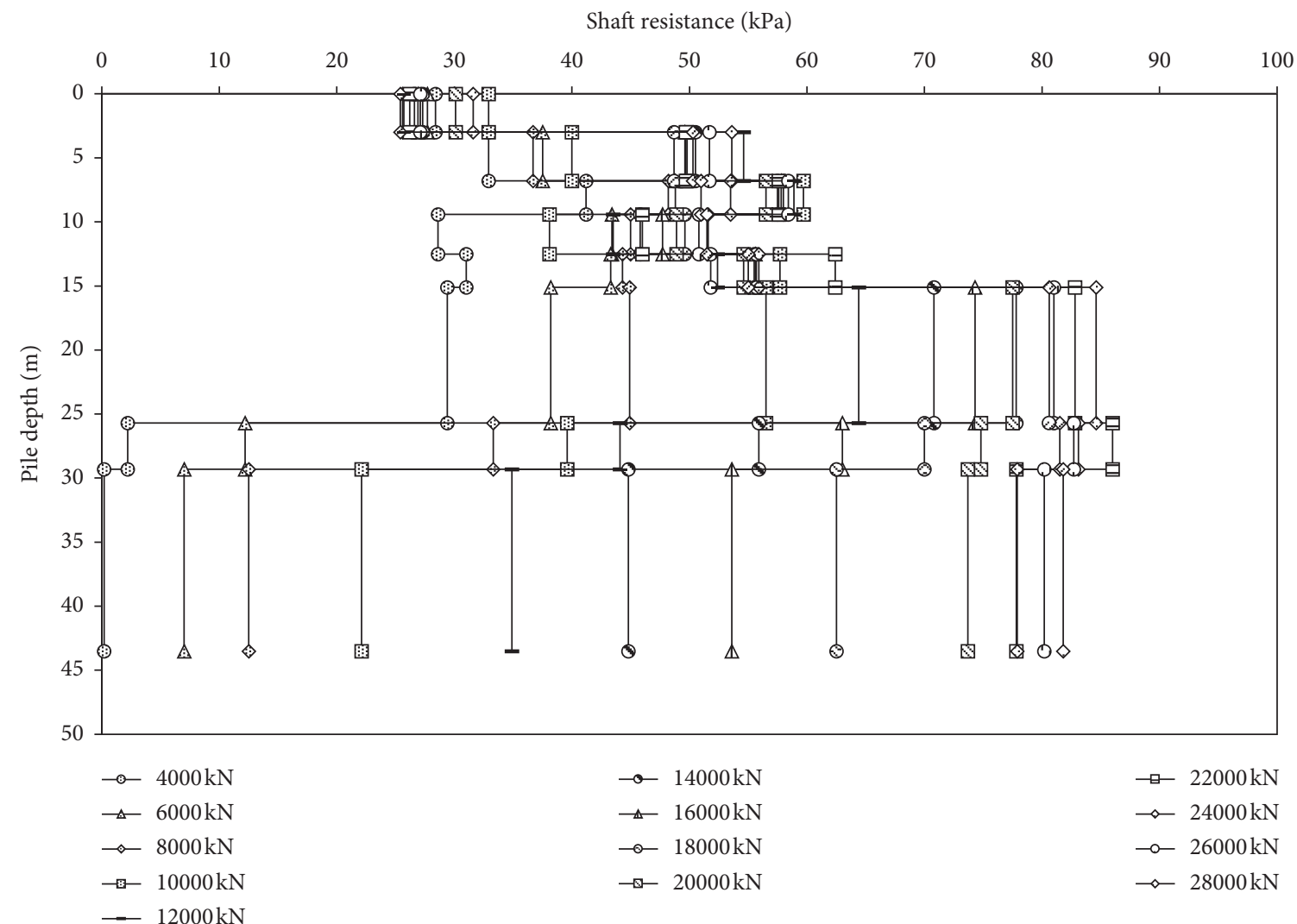

FIgURE 18: Shaft resistance distribution along the pile for P12.

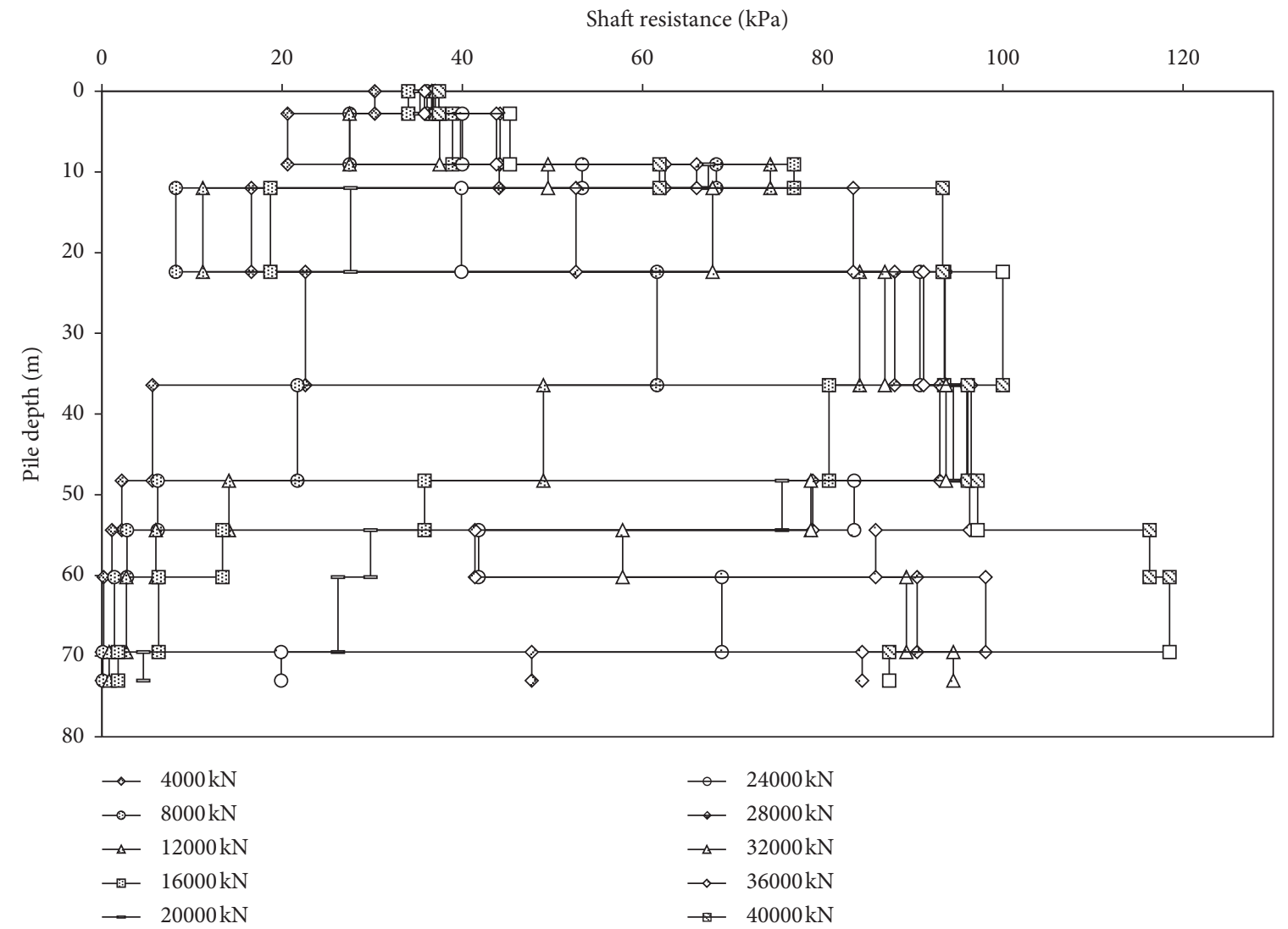

Figure 19: Shaft resistance distribution along the pile for P66. 


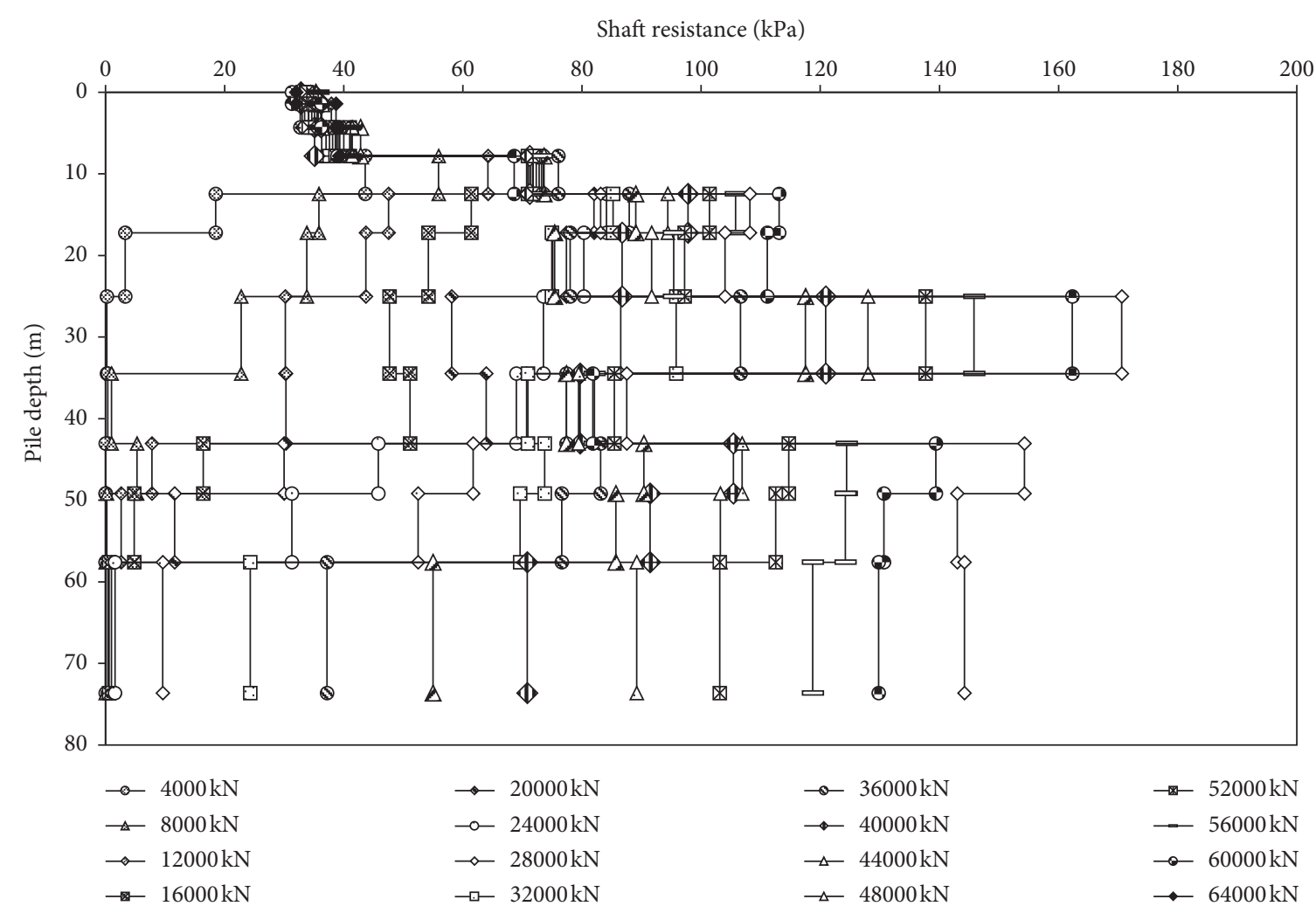

FIgURE 20: Shaft resistance distribution along the pile for P105.

layers almost fully developed (in each layer, the distances among vertical lines are very close to each other).

As shown in Figure 19, for the P66, before a loading of $16,000 \mathrm{kN}$ was applied, the shaft resistance was mainly provided from upper layers, and the bottom layer provided small shaft resistance, which was less than $5 \mathrm{kPa}$. Moreover, when connecting the shaft resistances with a smooth line, the resistance along the pile of the bottom layers (layers 7-10) illustrated an " $R$ " shape. Figure 19 also presents the fluctuation curves of layer 3 , where the shaft resistance softening and hardening were observed.

The shaft resistance distribution of $\mathrm{P} 105$ is represented in Figure 20. It can be found that there was almost no shaft resistance from the bottom layer before $28,000 \mathrm{kN}$ was applied. Also, it can be seen that the layers 1,2, and 3 were fully developed firstly, and layers $4,5,6$, and 8 were developed later because the vertical lines' distances were very close. Similar to the findings obtained from Figure 18, the shaft resistance of layer 7 kept developing during the whole loading tests.

\section{Conclusion and Recommendations}

This paper has investigated the axial behaviour of super-long and large-diameter piles through performing SLTs. A newly developed reaction system was introduced, and three piles with various lengths and diameters were tested. The results demonstrated that the pile with the least capacity was P12, and the pile with the best capacity was P105. The settlement of P105 was mostly concrete deformation. The transferred load decreased along the pile length during each applied load, but the gradients were different. For most layers, when increasing the load, the shaft resistance developed from zero to a maximum value and was then maintained. Moreover, the shaft resistance from the upper layers developed first, and the shaft resistance from the lower part was not fully developed.

The soil layers around these three piles were mostly sand, which possesses a relatively high void ratio; thus, postgrouting technology is highly recommended to improve the ultimate bearing capacity. However, it is recommended that shaft and base grouting be applied to P66 and P12, while only shaft grouting be applied to P105. This is because P105 is a shaft-dominated pile or a pure-friction pile; thus, using base grouting to reinforce the pile toe cannot effectively increase the ultimate bearing capacity. Further, for P105, because the transferred load from the pile toe was observed to be relatively small, increasing the pile length would be inappropriate to increase the ultimate bearing capacity; thus, increasing the pile diameter is recommended.

\section{Data Availability}

The excel data of field tests used to support the findings of this study are available from the first author or the corresponding author upon request.

\section{Conflicts of Interest}

The authors declare that there are no conflicts of interest regarding the publication of this paper. 


\section{Acknowledgments}

Thanks are due to the Project of Jiaozuo Xingyang Yellow River Bridge of Shandong Luqiao Group Co., Ltd. for their support.

\section{References}

[1] J. B. Yang and Z. X. Zhong, "Research on load transfer mechanism of super-long pile," Chinese Journal of Geotechnical Engineering, vol. 20, no. 6, pp. 76-79, 1998, (In Chinese).

[2] T. J. Lin, H. J. Xiong, and L. Q. Wang, Pile Foundation Design Manual, China Architecture \& Building Press, Beijing, China, (In Chinese), 1999.

[3] L. J. Zhou, Z. A. I. Lu, and W. J. Wang, "Vertical load mechanism analysis and experimental research on super-long PHC pipe pile in soft clay," Applied Mechanics and Materials, vol. 204-208, pp. 471-478, 2012.

[4] D. D. Wang, L. F. Wang, and L. P. Zhang, "Experimental study on post grouting bearing capacity of large diameter bored piles," MATEC Web of Conferences, vol. 22, pp. 1-7, 2015.

[5] S.-J. Feng, S.-F. Lu, and Z.-M. Shi, "Field investigations of two super-long steel pipe piles in offshore areas," Marine Georesources \& Geotechnology, vol. 34, no. 6, pp. 559-570, 2016.

[6] S.-c. Li, Q. Zhang, Q.-q. Zhang, and L.-p. Li, "Field and theoretical study of the response of super-long bored pile subjected to compressive load," Marine Georesources \& Geotechnology, vol. 34, no. 1, pp. 71-78, 2016.

[7] C. M. Michael and C. Jae, Evaluation of Static Resistance of Deep Foundations (BDV31-977-05), University of Florida, Department of Civil and Coastal Engineering, Gainesville, FL, USA, 2017, https://trid.trb.org/view/1471523.

[8] X. L. Zhou, X. Fan, and Y. B. Ji, "Optimization design and analysis of super-long pile in deep soft soil foundation for Huzhou commercial and residential building," Electronic Journal of Geotechnical Engineering, vol. 19, pp. 3089-3098, 2014.

[9] J. H. Zhang, Z. L. Wang, and D. Q. Qiao, "Effects of bed thickness and shoulder resistivity on array induction tools," Applied Mechanics and Materials, vol. 687-691, pp. 1105-1108, 2014.

[10] X. J. Zou and M. H. Zhao, "Axial bearing behaviour of superlong piles in deep soft clay over stiff layers," Journal of Central South University of Technology, vol. 20, no. 7, pp. 1-16, 2016.

[11] L. Sun, T. Jia, S. Yan, W. Guo, Y. Ren, and Z. Lei, "Prediction of pile running during the driving process of large diameter pipe piles," Ocean Engineering, vol. 128, pp. 48-57, 2016.

[12] M. Oliaei and S. M. A. Ghotbi Siabil, "Dynamic behavior of large-diameter piles considering liquefaction under clay layer," Scientia Iranica A, vol. 24, no. 6, pp. 2665-2683, 2017.

[13] Y. Lu, Y. Tan, and H. Lan, "Full-scale load testing of 75-90-mlong post-grouted drilled shafts in Suzhou stiff clay," Journal of Testing and Evaluation, vol. 47, no. 1, pp. 284-309, 2019.

[14] M. Y. Zhang, H. Y. Gao, Y. Li, H. Z. Song, and W. T. Peng, "Effect of soil stiffness on bearing characteristics of largediameter and super-long steel pipe pile based on FLAC3D," Applied Mechanics and Materials, vol. 170-173, pp. 743-746, 2012.

[15] Z. Zhou, D. Wang, L. Zhang, and W. Ma, "Determination of large diameter bored pile's effective length based on Mindlin's solution," Journal of Traffic and Transportation Engineering (English Edition), vol. 2, no. 6, pp. 422-428, 2015.

[16] H. F. Xing, J. Wu, and Y. Luo, "Field tests of large-diameter rock socketed bored piles based on the self-balanced method and their resulting load bearing characteristics," European Journal of Environmental and Civil Engineering, vol. 23, no. 12, pp. 1535-1549, 2019.

[17] P. J. Hannigan, G. G. Goble, G. E. Likins, and M. L. Becker, Design and Construction of Driven Pile Foundations (FHWANHI-16-009), National Highway Institute (US), San Franciso, CA, USA, 2016, http://www.itd.idaho.gov/manuals/manual.

[18] ASTM International, Standard Test Methods for Deep Foundation under Static Load Compressive Load, ASTM International, West Conshohocken, PA, USA, ASTM-D-1143/D-07), 1994.

[19] Ministry of Construction of the People's Republic of China, Technical Code for Testing of Building Foundation Piles (JGJ 106-2014), National Standard of the People's Republic of China, Beijing, China, 2014. 